\title{
Retrospective Cohort Observational Study on the Single Best Perforator-Based Pacman Flap in the Reconstruction of Stage IV Sacral Region Pressure Ulcers
}

\author{
T. M. Balakrishnan $\quad$ Basker Kanagaraj Mariappan ${ }^{1} \quad$ J. Jaganmohan ${ }^{1}$ \\ 1Department of Plastic and Faciomaxillary Surgery, Madras Medical \\ Address for correspondence T. M. Balakrishnan, MBBS, MS, FRCS, \\ DNB, MCH, DNB, Department of Plastic and Faciomaxillary Surgery, \\ Madras Medical College, Old No 15, New No10, Thiruvalluvar Street, \\ Rangarajapuram, Kodambakkam, Chennai-24, Tamil Nadu, \\ India 600024 (e-mail: thalaiviri.b@gmail.com).
}

\begin{abstract}
Introduction Single best perforator-based Pacman flap (SBPBPF) fortifies the advancement and transposition flap biogeometry principles with robust blood supply of perforator flaps to provide cover for the sacral pressure sore of any dimension. This article describes the biogeometry and technique of raising the SBPBPF.

Aim To assess the outcomes of reconstruction of stage IV sacral pressure sore using the SBPBPF.

Materials and Methods A preliminary cadaver study was done in 24 gluteal specimens in fresh cadavers to determine the anatomical details of perforators of the perisacral region. From 2015 to 2017, 42 myelopathic patients (40 males and 2 females; quadriparetic $n=2$ and paraplegic/paraparetic $n=40$ ) underwent SBPBPF reconstruction of stage IV sacral pressure sore. Their documents were analyzed in this retrospective study. All were followed-up for an average period of 12.5 months.

Results Cadaver study revealed significant perforators arising from seven different source vessels in the perisacral region. In the clinical study, average size of the paddle harvested was $168 \mathrm{~cm}^{2}$ on a single best perforator. On an average, the size of the sin-

Keywords

- pressure sores

- perforator flaps

- single best perforator based Pacman flap

- biogeometry of

Pacman flap gle best perforator harvested with the flap was $1.5 \mathrm{~mm}$. None had early failures of flaps. Thirty-nine patients had well-settled flaps at the end of follow-up period except three (7\%) who developed late recurrence due to loss of compliance with offloading instructions. Two experienced mild collections (flap complication rate was $4.76 \%$ ) in the immediate postoperative period that healed uneventfully. The overall complication rate was $11.9 \%$. Conclusion SBPBPF is an excellent addendum to reconstructive tool for stage IV sacral pressure sores.
\end{abstract}

\section{Introduction}

Sacral pressure sores are the most common pressure ulcers seen in the bedridden, debilitated, altered sensorium and paraplegic patients..$^{1-4}$ Pressure sores prolong the hospital stay of the patient and impose significant impact on the healthcare economy and policies. ${ }^{1-5}$ Therefore, early reconstruction of the pressure sores improves early recuperation and functional recovery of these patients. ${ }^{4-6}$ The essential requirements of the flaps used in the reconstruction of the pressure sores are-1. Should not violate the prospectus of adjacent locoregional flaps. 2. Should have enough volume of published online July 13,2020
DOI https://doi.org/

$10.1055 / \mathrm{s}-0040-1714318$

ISSN 0970-0358.
C2020 Association of Plastic Surgeons of India
License terms

()(1) $\Theta \circledast$ 
well-vascularized tissues to fill cavities and cull the infection (as most of these excised pressure sore wounds are deep and also contaminated). 3. Should have the potential of refashioning of the flap in the events of recurrences (which are common phenomena in pressure sore management). There are many regional and local flaps that can be used for the stage IV sacral pressure sore (NPUAP staging) ${ }^{7}$ reconstruction. But most of the time the ostectomy and excision of stage IV sacral pressure sores leave only shallow or moderate depth defects. Therefore, the need is thickness matching pliable flap, which can fit over the craniocaudally and transversely convex-exposed sacrum.

Bonomi $^{8}$ et al introduced the perforator-based Pacman flap (named so after the shape of the flap) (-Fig. 1) for reconstruction of pressure sores. In his article, he revealed that Pacman flap could be based on multiple perforators to harvest large flap. He also elicited that multiple perforators restrict the primary movement; also, they did not define the biogeometry of the flaps. In this article, the author addresses the restriction of primary mobility of the flap by harvesting the Pacman flap based on the single best perforator, and stage IV sacral pressure sores are reconstructed with it. The single best perforator-based Pacman flap (SBPBPF) consolidates the basic biogeometric principles of transposition and advancement flaps with the most recent concepts of perforator-based flap. The SBPBPF provides more excursion to the flap with supranormal homogenized blood supply (based on the physiology of perforator flaps elicited by Blondeel et al ${ }^{9}$ and Rubino et $\mathrm{a}^{10}$ ). The author also defines the biogeometrical steps for the SBPBPF in this article.

\section{Aim}

To assess the outcomes of reconstruction of stage IV sacral pressure sore using the SBPBPF.

\section{Materials and Methods}

Institutional ethical committee approval was obtained for both the clinical and cadaver studies.

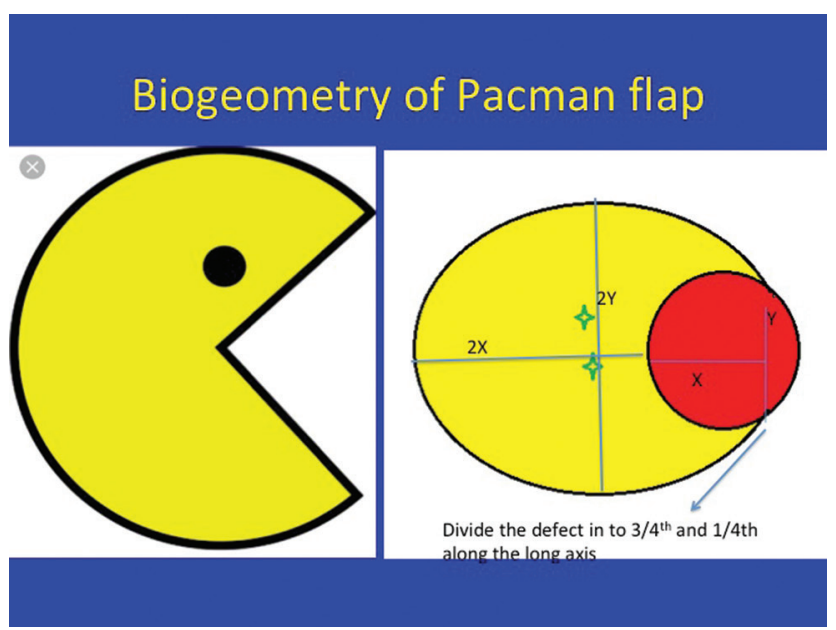

Fig. 1 Shape of open Pacman (left) and biogeometry of Pacman flap (right).

\section{Cadaver Study}

A cadaver study was conducted to determine the available number of perforators as well as their origin and dimensions in the perisacral region. Twenty-four gluteal specimens were studied in 12 fresh cadavers. Red lead oxide with gelatin gel was injected into the common iliac arteries, and methylene blue was injected into the common iliac veins under low pressure. After freezing for 24 hours, the cadavers were dissected. Only those perforators, which were within $10 \mathrm{~cm}$ from the perimeter of the sacrum and over the sacral region were studied ( - Fig. 2). As a prelude to the dissection, the gluteal triangle was marked with palpatory identification of the following bony landmarks: posterior superior iliac spine, greater trochanter cranial tip, and ischial tuberosity (-Fig. 2). The lateral sacral perforators were medial to this triangle. The line extending from the posterior superior iliac spine to ischial tuberosity (PSIS to IT line) was divided into thirds. The superior gluteal vessels usually were emerging at the junction of upper thirds and middle thirds of this PSIS to IT line. Inferior gluteal vessels usually were emerging at the junction of middle third and lower third junction of this line. The perforators from internal pudendal and medial circumflex vessels were expected medial and inferior to IT bony landmarks. Ileolumbar vessel perforators were usually superlateral to the gluteal triangle. The number of perforators arising from the superior gluteal vessels, inferior gluteal vessels, internal pudendal vessels, first perforator of profunda femoris vessels, iliolumbar/lumbar vessels, medial circumflex femoral vessels, and lateral sacral vessels were examined. The perforators were identified at the suprafascial level and dissected retrograde up to the source vessels (-Figs. 3 and 4). The perforators were measured with the caliper at the fascial level.

\section{Clinical Study}

From 2015 to 2017, 42 myelopathic patients underwent the SBPBPF reconstruction of stage IV sacral pressure sore. Written informed consent for surgery, anesthesia, including consent for the photography, and their display for research purposes were obtained. It is a retrospective cohort study.

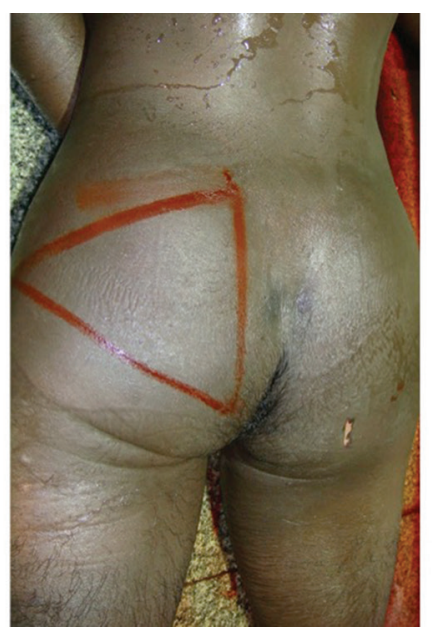

Fig. 2 Gluteal triangle marked on the cadaver. 


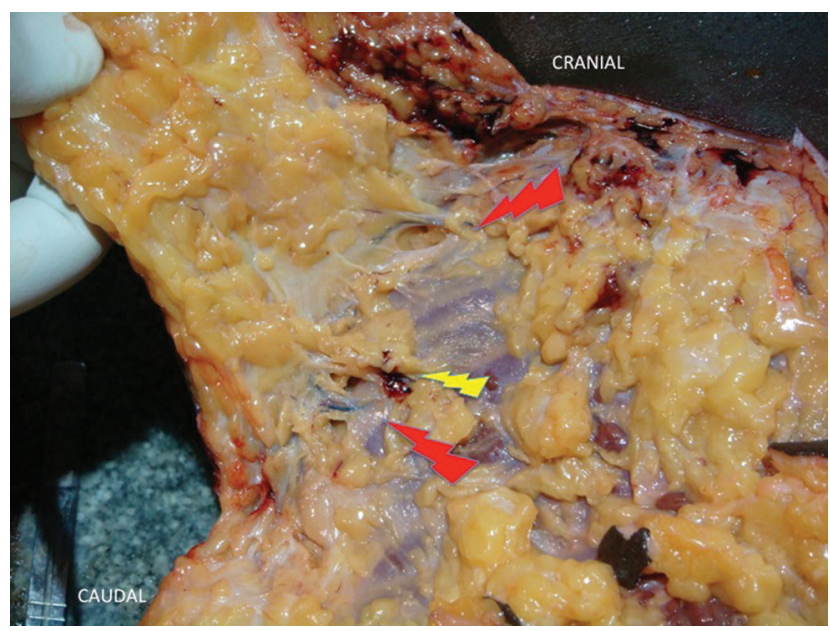

Fig. 3 Cadaver dissection showing perforators at fascial level (red marker) and clunial neurocutaneous perforator (yellow marker).

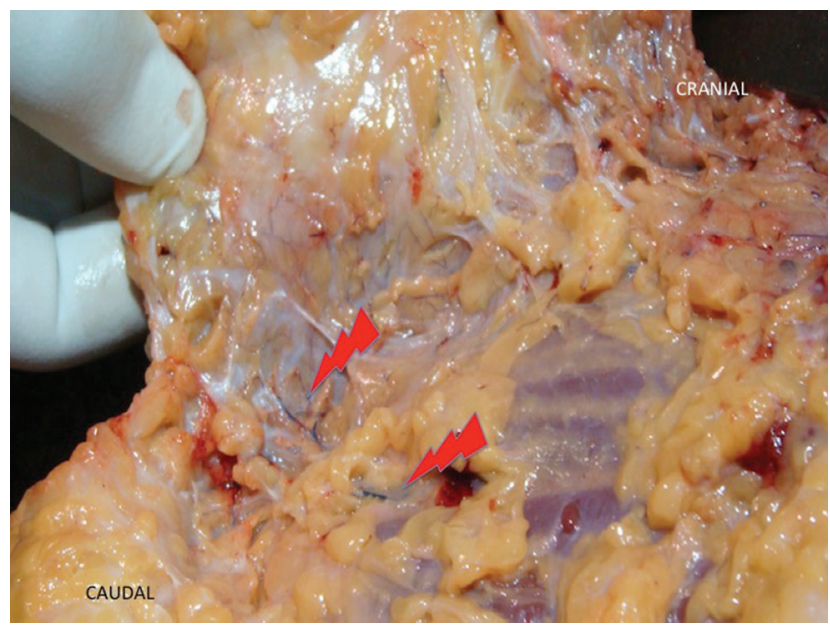

Fig. 4 Cadaver dissection showing the beginning of periperforator dissection toward source vessel.

\section{Inclusion Criteria}

1. Myelopathic patients with stage IV sacral pressure sore.

2. Any size or shape defect but not with large subfascial void.

\section{Exclusion Criteria}

1. Radiological, histopathological, and microbiological evidence of osteomyelitis of sacrum.

2. Poor general condition and comorbid illnesses.

\section{Preoperative Preparation}

All the patients were improved of their nutritional status by enteral feeding with first class proteins and adequate calories. Nineteen patients were preoperatively administered blood transfusion to improve their hemoglobin status. All of them had multiple sittings of preliminary wound debridement to get rid of dead, devitalized, and suppurated tissues. On an average, 2.5 number of debridement procedures were preoperatively performed. They were all done under local monitored analgesia care. They were taken for definitive surgical intervention with improved nutritional and wound status. Using handheld 10 Mega Hertz (MHz) Doppler, all the perforators in the vicinity of ulcers were located and marked.

\section{Surgical Technique}

The following are the five biogeometrical steps of the SBPBPF:

\section{Selection of the Pacman Flap}

Any size or shape defect can be reconstructed but not with large subfascial void.

\section{Siting of the Flap}

Although the flap has the freedom of being sited at any 360 degrees around the defect, it is sited in such a way that wound should not be completely aligned to the natal cleft (no wound in the midline and submerging into the natal cleft, as it leads to recurrences, macerations, dehiscence, and infections) and also not extending onto any other adjacent bony prominences. All the perforators were located by handheld Doppler in the vicinity of the defect.

\section{Designing the Flap}

After siting the flap, the defect is divided into three fourth and one fourth along the long axis in such a way that the three fourth of the defect lies adjacent to the prospective area of the flap. The distance along the long axis from the edge of the defect to the three fourth and one fourth junction is taken as " $\mathrm{X}$ " $\mathrm{cm}$. The short axis of the defect is measured orthogonal to the long axis and taken as "Y" $\mathrm{cm}$. Along the long axis of the defect, a point is taken in such a way that it lies $2 \mathrm{X} \mathrm{cm}$ from the edge of the defect (which is the apex of SBPBPF). Now, two tangential curvilinear lines are drawn from the three fourth and one fourth junction to the apex of the flap with the maximum short dimension of the flap as $2 \mathrm{Y} \mathrm{cm}$ (parallel to the $\mathrm{y}$ axis of the defect) ( - Fig. 1). All the perforators within the marking of the flap were noted.

\section{Construction of the Flap}

Nondelineating incision was made and subfascial dissection was started. All the possible perforators were located, and the incision was completed. For choosing the single best perforator, the following criteria were considered: 1 . Pulsatile. 2. Larger in size. 3. At least one venae comitans. 4. Ability to perfuse the whole flap after clamping others without any congestion. 5. Even the eccentrically located perforators in relation to the paddle were included, as they do not affect the survival of the flap. 6 . The perforators with clunial cutaneous nerves were avoided because they are always associated with trivial neurocutaneous perforator ( - Fig. 3 ). Adequate periperforator dissection was done to allow enough length of the pedicle, permitting the tensionless primary movement and inset of the flap without any acute kinking and twist. Standard mathematical formula for surface area of ellipse (main portion of Pacman) and triangle (two limbs of Pacman) were used to arrive at the final surface area of Pacman flap. Perforator's size was measured at subfascial level using the calipers routinely in all clinical cases. 

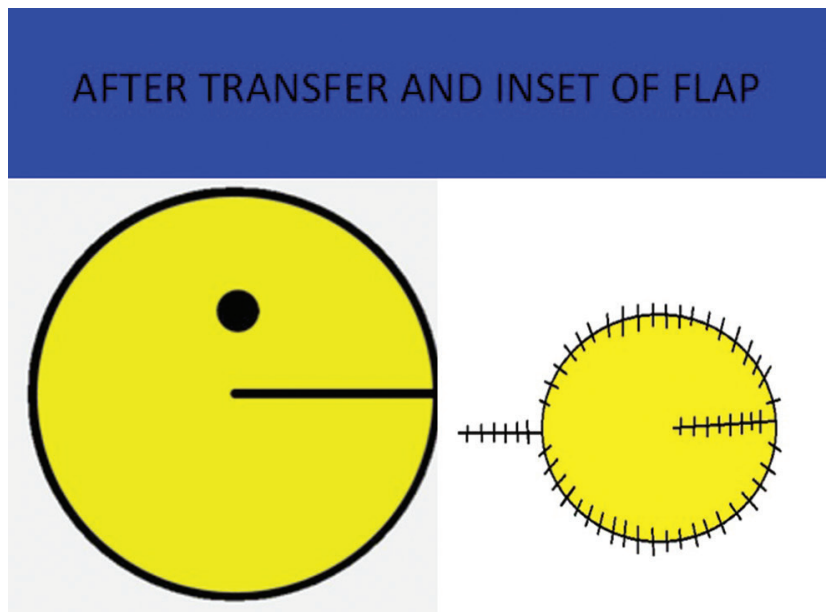

Fig. 5 Shape of closed Pacman (left) and final inset of the flap (right).

\section{Transfer and Inset of the Flap}

V-Y advancement was done after closing the mouth of Pacman by transposition. Secondary defect was closed. and tension-free inset of the flap was given ( - Fig. $\mathbf{5}$ ).

\section{Post-operative Management}

Segmullar drains were removed on the 3rd or 4th postoperative day. All the patients had perioperative and postoperative antibiotic therapy, based on the institutional protocol, and subsequently changed over to directive antibiotic therapy based on antibiogram. In the postoperative period, the surgical team, with change of posture every 2 hours, strictly maintained position chart. Positions were changed between right lateral, left lateral, exaggerated right lateral, exaggerated left lateral, and sitting posture (in selected cases). All of them were nursed in low air loss bed. The surgical team maintained postoperative nutrition.

\section{Follow-up}

All were followed-up for an average period of 12.5 months by the paramedical and surgical teams.

\section{Case Illustration 1}

A 35-year-old paraplegic patient presented with sacral pressure sore, who underwent "pseudotumor" excision with ostectomy of median spines of sacrum, resulting in a shallow depth defect measuring $15 \times 7.5 \mathrm{~cm}$ (-Fig. 6). A Pacman flap was designed on the left side of the patient measuring $17 \times$ $8.5 \mathrm{~cm}$ (-Fig. 6). It was harvested on the single best perforator arising from superior gluteal vessels ( - Fig. 6). It was advanced and closed. Flap settled well on the 11-month follow-up (-Fig. 6).

\section{Case Illustration 2}

A 42-year-old quadriparetic patient presented with multiple sacral pressure sores ( $\boldsymbol{- \text { Fig. }} \mathbf{7}$ ). There was history of pelvic fracture in addition to the vertebral fracture. There were no suitable perforators on the preoperative Dopplering on the left hemipelvis side (due to pelvic fracture). Therefore, it was

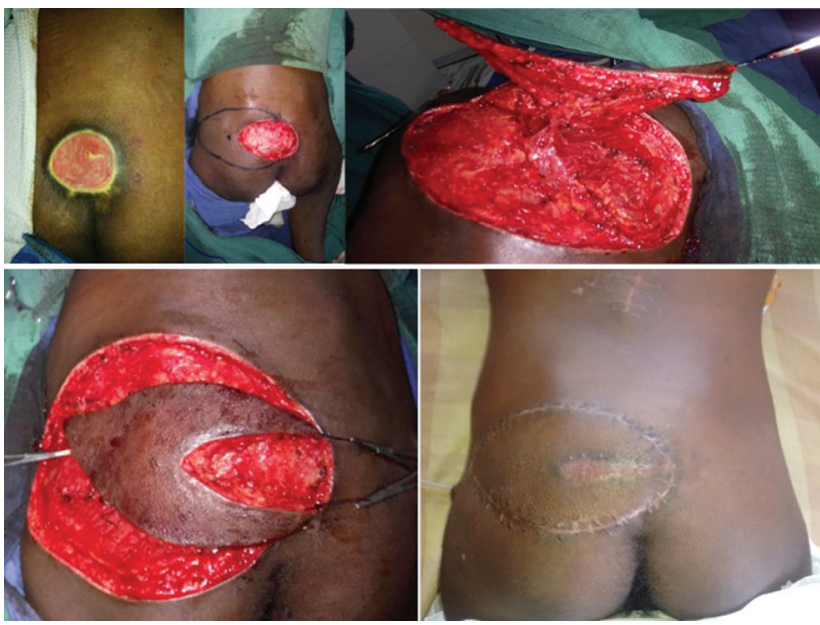

Fig. 6 Case 1 illustrations. Left upper: Preoperative picture with stage IV sacral pressure sore; Upper middle: Intraoperative picture showing excised defect with flap and perforator marking; Right upper: Intraoperative picture showing harvest of Pacman flap on single best perforator; Left lower: Intraoperative picture showing primary movements of Pacman flap; Right lower: Follow-up picture at 11 months.

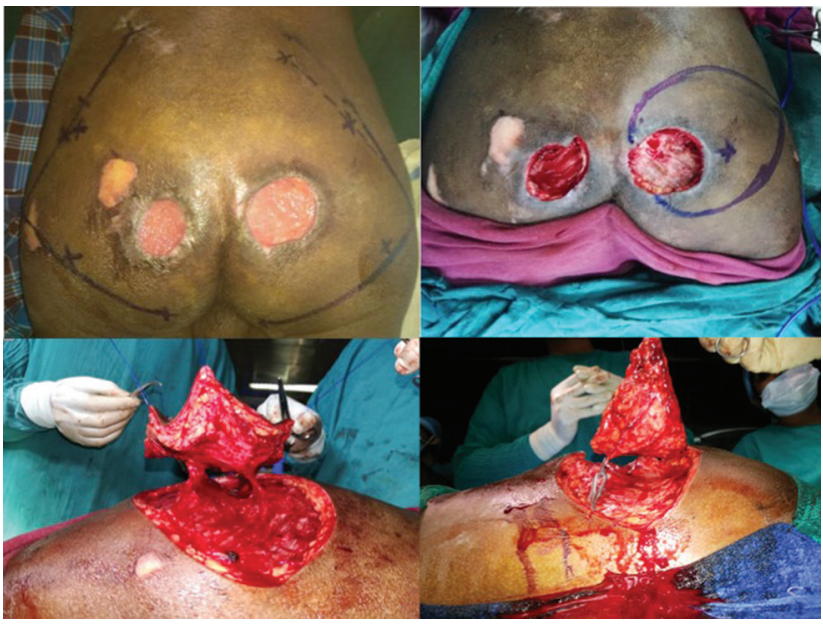

Fig. 7 Case 2 illustrations. Left upper: Preoperative picture showing multiple sacral pressure sores; Right upper: Intraoperative picture showing excised defects with flap marking (right side of the patient); Left lower: Intraoperative picture showing harvest of Pacman flap on multiple perforators; Right lower: Intraoperative picture showing microclamping of the perforator before choosing the single best perforator.

decided for rotation flap on the left side and SBPBPF on the right side, where suitable perforators were found preoperatively ( - Fig. 7). Following the "pseudotumor" excision of the ulcers, two defects measuring $5 \times 6 \mathrm{~cm}$ on the left side and $6 \times 6.5 \mathrm{~cm}$ on the right side were present ( - Fig. 7). There was a superficial abrasion $(4 \times 2.5 \mathrm{~cm})$ superior and lateral to left side pressure sore, which was planned for conservative secondary healing. On exploration on the right side, there were three perforators, one of them measuring $2.5 \mathrm{~mm}$ (arising from Internal pudendal vessels), and two of them measuring $1.5 \mathrm{~mm}$ (arising from inferior gluteal vessels) ( - Fig. 7). All of them were associated with two vena commitantes. After microclamping of small perforators, there was good perfusion 
from single large perforator from the internal pudendal vessels (although it was eccentrically situated) ( - Fig. 7 ). So, the Pacman flap was harvested based on this single best perfora-

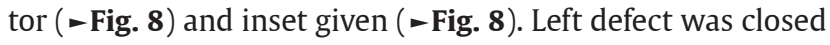
by rotation flap ( - Fig. 8). Flaps settled well and followed-up for a period of 12 months ( - Fig. 8).

\section{Results}

\section{Cadaver Study}

- Table 1 shows the results of the cadaver study. One important inference derived from the cadaveric study was that the perforators found running with the clunial cutaneous nerves were very trivial ( $\bullet$ Fig. 3 -marked by yellow pointer).

\section{Clinical Study}

- Table 2 shows the results of the clinical study. The average age in the quadriparetic group was 42.5 years, and in paraplegic/paraparetic group, it was 35 years. The average size of the defect in the quadriparetic group was $142 \mathrm{~cm}^{2}$, and in the paraplegic/paraparetic group. it was $152 \mathrm{~cm}^{2}$. The average

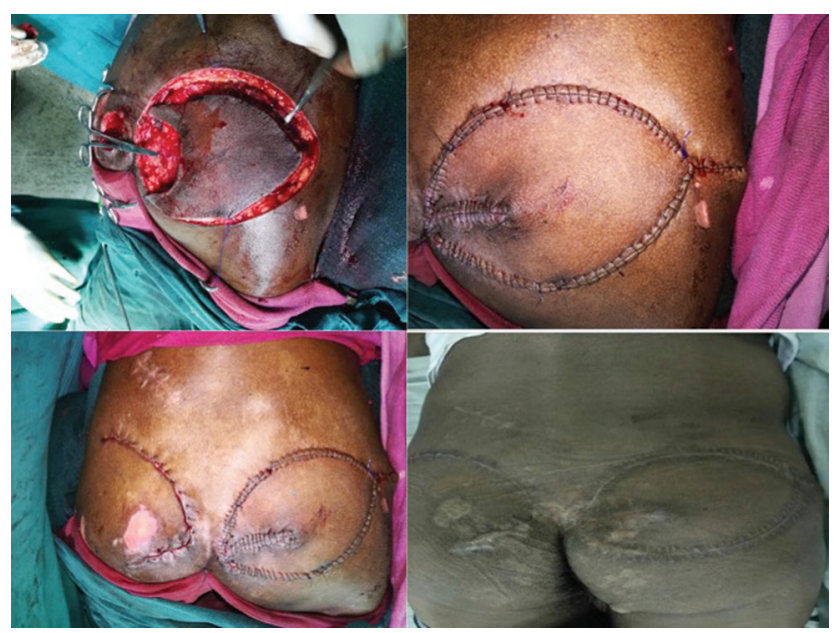

Fig. 8 Case 2 illustrations. Left upper: Intraoperative picture showing flap being harvested on the single best perforator; Right upper: Intraoperative picture showing the primary movement of Pacman flap and final inset; Left lower: Case 2: intraoperative picture showing final inset of all flaps; Right lower: Case 2: 12 months postoperative follow-up picture. size of the cutaneous paddle harvested was $160 \mathrm{~cm}^{2}$ in the quadriparetic group and $176 \mathrm{~cm}^{2}$ in the paraplegic/paraparetic group. On an average, $1.5 \mathrm{~mm}$ was the size of single best perforators harvested with the flap. The largest flap harvested was $16 \times 14 \mathrm{~cm}$ and the smallest flap was $5 \times 5 \mathrm{~cm}$. A total of 39 patients had well-settled flaps at the end of the follow-up period, except three (7\%), who developed late recurrence due to loss of compliance with offloading instructions. None experienced failures of flaps. Two patients had mild collections in the immediate postoperative period that healed uneventfully. The overall complication rate was $11.9 \%$ (-Table 1). On an average, suture removal done at 16.5 days.

\section{Cadaver Study Analysis}

In the study ( - Table 2 ), the mean size of the perforator was highest for iliolumbar vessels axis $(1.5 \mathrm{~mm})$ and lowest for IPA and first perforator from profunda femoris vessels (1.1 $\mathrm{mm}$ respectively). The average number of perforators was highest for IGA (15) and lowest for medial circumflex femoral vessels ( 1 ).

\section{Clinical Study Analysis}

In the study, and in - Table 1, two subjects were quadriparetic, and 40 subjects were paraparetics. Among the former, both of them were males, and among the 40 paraparetics, 38 of them were male and 2 of them were female. There was no significant difference in sex distribution. Among quadriparetics, the mean age was 42.5 years, mean average size of defects was $142 \mathrm{~cm}^{2}$, and mean average size of the flaps was $160 \mathrm{~cm}^{2}$. Among paraparetics, the mean age was 35 years, mean average size of defects was $160 \mathrm{~cm}^{2}$, and mean average size of the flaps was $176 \mathrm{~cm}^{2}$. There was no difference in age distribution between quadriparetics and paraparetics. There was significant difference in average size of defects and average size of the flaps between quadriparetics and paraparetics, i.e., paraparetics had higher average size of defects and average size of the flaps compared with quadriparetics. There was no significant difference in source vessels between quadriparetics and paraparetics. There was significant difference in seroma between quadriparetics and paraparetics i.e., $50 \%$ of quadriparetics had seroma and $2.5 \%$ had seroma in

Table 1 Demographics of the patients who underwent reconstruction with SBPBPF

\begin{tabular}{|l|l|l|l|l|l|l|l|}
\hline $\begin{array}{l}\text { Myelopathy } \\
\text { pathology }\end{array}$ & $\begin{array}{l}\text { Number of } \\
\text { patients and sex } \\
\text { distribution }\end{array}$ & $\begin{array}{l}\text { Average } \\
\text { age }\end{array}$ & $\begin{array}{l}\text { Average } \\
\text { size of } \\
\text { defects } \\
\left(\mathrm{cm}^{2}\right)\end{array}$ & $\begin{array}{l}\text { Average } \\
\text { size of } \\
\text { the flaps } \\
\left(\mathrm{cm}^{2}\right)\end{array}$ & Source vessels & $\begin{array}{l}\text { Early } \\
\text { complications }\end{array}$ & $\begin{array}{l}\text { Late } \\
\text { complications }\end{array}$ \\
\hline Quadriparetic & $2(\mathrm{M}=2 ; \mathrm{F}=0)$ & 42.5 & 142 & 160 & $\begin{array}{l}\text { SGA }(n=1) ; \\
\text { IGA }(n=1)\end{array}$ & Seroma $(n=1)$ & Nil \\
\hline $\begin{array}{l}\text { Paraplegics/ } \\
\text { Paraparetics }\end{array}$ & $40(\mathrm{M}=38 ; \mathrm{F}=2)$ & 35 & 152 & 176 & $\begin{array}{l}\text { SGA }(n=14) ; \\
\text { IGA }(n=12) ; \\
\text { IPA }(n=6) ; \\
\text { MCFA }(n=3) ; \\
\text { ILA }(n=3) ; \\
\text { FPPFA }(n=2)\end{array}$ & Seroma $(n=1)$ & Recurrence $(n=3)$ \\
\hline
\end{tabular}

Abbreviations: F, female; FPPFA, first perforator of profunda femoris artery; IGA, inferior gluteal artery; ILA, iliolumbar artery; M, male; MCFA, medial circumflex femoral artery; SGA, superior gluteal artery. 
Table 2 Data of cadaveric study of perisacral perforators

\begin{tabular}{|l|l|l|l|}
\hline Vessel axis & $\begin{array}{l}\text { Mean size of perforators } \\
\text { (mms) }\end{array}$ & $\begin{array}{l}\text { Average number of } \\
\text { perforators }\end{array}$ & Type of perforators \\
\hline SGA & 1.3 & 12 & MCP \\
\hline IGA & 1.4 & 15 & MCP and few SCP \\
\hline IPA & 1.1 & 3 & DCP \\
\hline $\begin{array}{l}\text { First perforator from profunda } \\
\text { femoris vessels }\end{array}$ & 1.1 & 2 & MCP \\
\hline $\begin{array}{l}\text { Medial circumflex femoral } \\
\text { vessels }\end{array}$ & 1.2 & 1 & MCP and few SCP \\
\hline Ilio-lumbar vessels & 1.5 & 2 & MCP \\
\hline Lateral sacral vessels & 1.2 & 2.125 & MCP \\
\hline
\end{tabular}

Abbreviations: DCP, direct cutaneous perforator; IGA, inferior gluteal artery; IPA, internal pudendal artery; MCP, musculocutaneous perforator; SCP, septocutaneous perforator; SGA, superior gluteal artery.

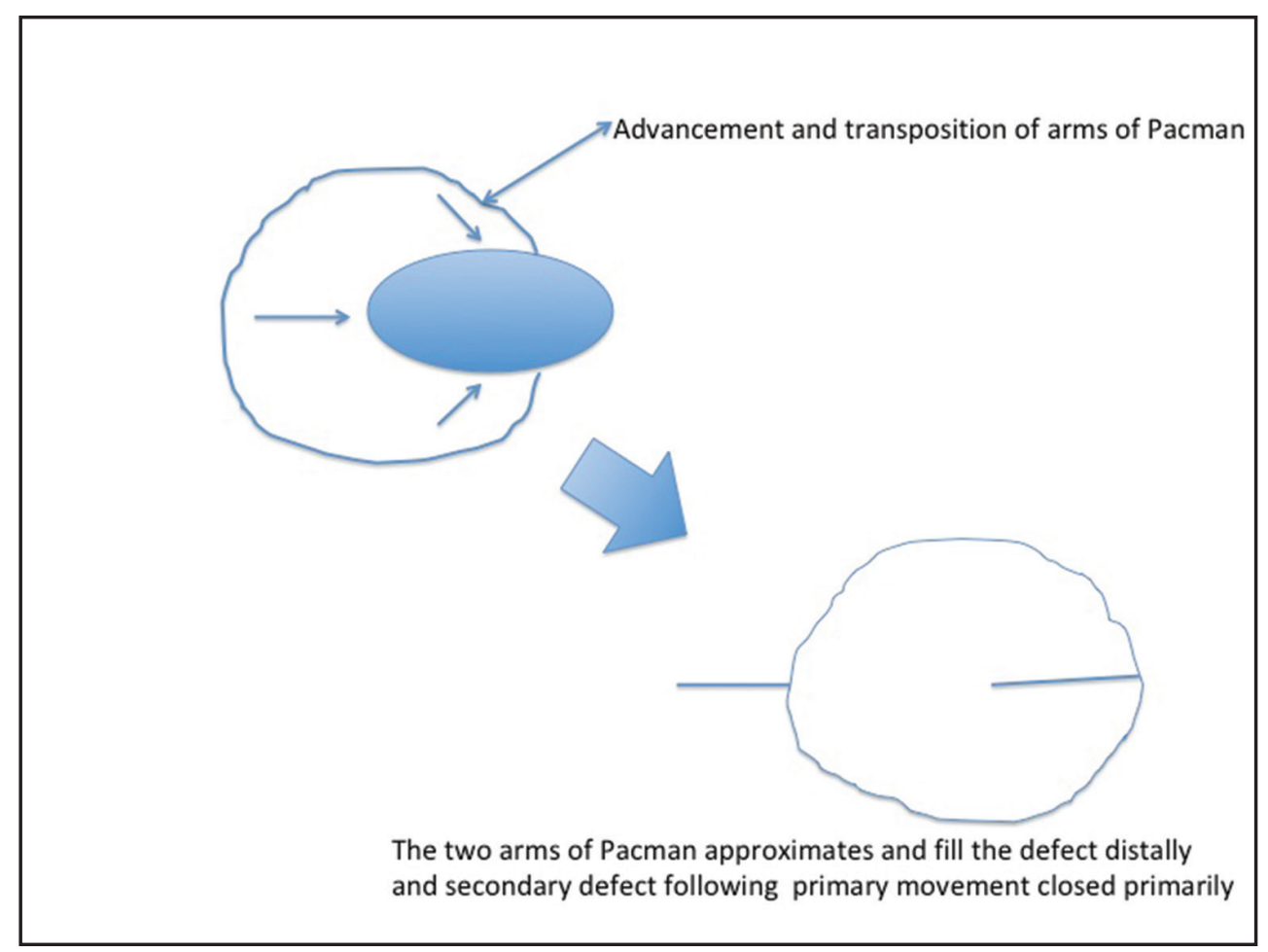

Fig. 9 Artwork depicting the primary movements of the Pacman flap.

paraparetics. There was no significant difference in late complications between quadriparetics and paraparetics.

\section{Discussion}

In the cadaver dissection performed by the author, the sizeable perforators in the vicinity of the sacrum were from seven different sources. According to an angiographic study on five cadavers by Koshima et al, ${ }^{11}$ the main cutaneous perforators in the gluteal region were reported arising from the superior and inferior gluteal arteries. Also, we found that those neurocutaneous perforators that accompany clunial nerves are trivial and not reliable.

Pressure sores always pose a difficult challenge for plastic surgeons, especially in myelopathic crippled patients with poor wound healing capacity due to malnutrition, poor general condition, clinical depression leading to poor intake, and incontinent bladder and bowel. Even when one achieves wound healing after removing all these hurdles, the recurrence is high on the list of late complications. Many surgical methods have been used for sacral pressure sores, including primary closure, skin grafting, local random flaps, muscle flaps, fasciocutaneous flaps, and free flaps. ${ }^{12-15}$ However, the degree of mobility of a $\mathrm{V}-\mathrm{Y}$ advancement flap is dependent on the laxity of the underlying subcutaneous tissue. This is an important disadvantage of traditional $\mathrm{V}-\mathrm{Y}$ advancement flap and limits its usage. In this article, the author describes SBPBPF, which favors the increase in mobility due to consolidation of the primary movements of $\mathrm{V}-\mathrm{Y}$ advancement flap, transposition flap (-Fig. 9), and single best perforator-based 
flap, reinforced with robust homogenized blood circulation of the perforator flap. Perforator-based flap overcomes mobility restriction problem, with a further modification of Pacman-like shape to improve the covering surface area of the flap. The author, in this study, elicits the benefits of SBPBPF over the multiple perforator-based Pacman flaps introduced by Stefano Bonomi. ${ }^{8}$ This is the only closely relatable study to the author's current study. This is the first clinical study on the single best perforator-based Pacman flap, and the author showed in this study that the success rate is better than Bonomi et al. The age and gender distribution in the Bonomi et al study were comparable to the current author's study. Flap success rate in the author's study was $100 \%$, and in the Bonomi et al study, it was $92.3 \%$. Flap complication rate in the author's study was 4.76\%, and in Bonomi et al study, it was $10 \%$. The average size of the cutaneous paddle (harvested on the single best perforator) in the author's study was $168 \mathrm{~cm}^{2}$, and in the Bonomi et al study (harvested on the multiple perforators), it was $156 \mathrm{~cm}^{2}$. In addition, author defines the biogeometry of the SBPBPF in this article. The higher success rate of the author's study could be related to the homogenized blood circulation ${ }^{9,10}$ offered by the SBP flap and its tension-free excursion. Although the lateral sacral vessel perforators were dissected in the cadaver study, it was either hardly of any considerable size or lying within the sacral pressure sore itself, defying its use. ${ }^{16}$

We harvested the large flap (because of incorporation of tissues adjacent to the defect) with homogenized supranormal blood supply (because of single best perforator flap physiology), which was obtained by our modification of conventional Pacman flap. Also, there is more freedom for advancement when we free the perforators by periperforator dissection and basing it on the single best perforator. In addition, the author had established (based on the cadaver dissection) the feasibility of raising the SBPBPF on six different source vessels for the reconstruction of sacral pressure sores in this clinical study (superior gluteal vessels, inferior gluteal vessels, ileolumbar vessels, medial circumflex femoral vessels, internal pudendal vessels, and first perforator from profunda femoris).

Although the author's study is of small scale, the strength of the study is establishment of biogeometrical steps and safe methods of elevation of the flap to implement stable cover of the sacral pressure sores. Pressure sores often lead to health, personal, family, and social problems, particularly in paraplegic and quadriplegic patients. Many different operative options have been used to treat pressure sores. Ever since the perforator flaps were introduced for the reconstruction of the posterior midline defects by Kroll et al, ${ }^{12}$ there is burgeoning interests in the use of these flaps. However, we advocate the preferential use of the SBPBPF for the reconstruction of stage IV sacral pressure sores for the following reasons: 1. This flap is easy to perform. 2 . It is safe and very effective. 3. Shorter operative time (in the perspective of other perforator/ propeller flaps). 4. Low-donor site morbidity. 5. Good preservation of muscle. 6 . Offers remarkable excursion when based on the single best perforator. The limitation of this flap is that it cannot be used for sacral pressure sore with subfascial excision void and in recurrent cases.

\section{Conclusion}

The SBPBPF is another new addendum for the reconstruction of sacral pressure sores as it combines the bests of $\mathrm{V}-\mathrm{Y}$ flaps, perforator flaps, and transposition flaps, which makes this flap a viable choice for sacral pressure sore coverage.

\section{Financial Support Declaration}

Nil.

\section{Conflict of Interest}

Nil.

\section{References}

1 David G. Armstrong. Broadcast on pressure ulcer best practices at the NPUAP (serial online). Available at: https:// diabeticfootonline.com/2019/05/02/keckmedusc-hosts-cmsgov-broadcast-on-pressure-ulcer-best-practices-thenpuap/. Accessed August 21, 2019

2 VanGilder C, Amlung S, Harrison P, Meyer S. Results of the 2008-2009 International Pressure Ulcer Prevalence Survey and a 3-year, acute care, unit-specific analysis. Ostomy Wound Manage 2009;55(11):39-45

3 Meehan M. National pressure ulcer prevalence survey. Adv Wound Care 1994;7(3):27-30, 34, 36-38

4 Bennett G, Dealey C, Posnett J. The cost of pressure ulcers in the UK. Age Ageing 2004;33(3):230-235

5 Reddy M, Gill SS, Kalkar SR, Wu W, Anderson PJ, Rochon PA. Treatment of pressure ulcers: a systematic review. JAMA 2008;300(22):2647-2662

6 Sung YH, Park KH. Factors affecting the healing of pressure ulcers in a Korean acute care hospital. J Wound Ostomy Continence Nurs 2011;38(1):38-45

7 Neligan PC. Plastic surgery. New York, USA: Elsevier; 2018

8 Stefano Bonomi MD, André Salval MD, Federica Brenta MD, Vincenzo Rapisarda MD, Fernanda Settembrini MD. The Pacman perforator-based V-Y advancement flap for reconstruction of pressure sores at different locations. Ann Plast Surg 2015;77(3):324-331

9 Blondeel PN, Morris SF, Hallock GG, Neligan PC. Perforator flaps Anatomy, Technique, \& Clinical Applications. 2nd ed. St. Louis, Missouri: Quality Medical Publishing, Inc; 2003

10 Rubino C, Ramakrishnan V, Figus A, Bulla A, Coscia V, Cavazzuti MA. Flap size/flow rate relationship in perforator flaps and its importance in DIEAP flap drainage. J Plast Reconstr Aesthet Surg 2009;62(12):1666-1670

11 Koshima I, Moriguchi T, Soeda S, Kawata S, Ohta S, Ikeda A. The gluteal perforator-based flap for repair of sacral pressure sores. Plast Reconstr Surg 1993;91(4):678-683

12 Kroll SS, Rosenfield L. Perforator-based flaps for low posterior midline defects. Plast Reconstr Surg 1988;81(4):561-566

13 Yamamoto Y, Tsutsumida A, Murazumi M, Sugihara T. Longterm outcome of pressure sores treated with flap coverage. Plast Reconstr Surg 1997;100(5):1212-1217

14 Cushing CA, Phillips LG. Evidence-based medicine: pressure sores. Plast Reconstr Surg 2013;132(6):1720-1732

15 Lemaire V, Boulanger K, Heymans O. Free flaps for pressure sore coverage. Ann Plast Surg 2008;60(6):631-634

16 Durgun M, Bas S. Repair of sacral and ischial region defects with lateral sacral artery perforator flaps. Ann Plast Surg 2019;82(3):304-309 